ISSN: 1110-5623 (Print) - 2090-0570 (Online)

\title{
EFFECT OF LIGHT-EMITTING DIODE (LED) LIGHT COLOR ON TESTICULAR GROWTH, CIRCULATING TESTOSTERONE CONCENTRATION AND SPERM QUALITY IN DANDARAWI ROOSTERS
}

\author{
M. A. M. Sayed* and Mostafa Galal Abdelfatah
}

Dep.of Poult. Prod.Fac. of Agric., Assiut Uni., Assiut 71526, Egypt.

Corresponding Author*: E-mail: mohamed.sayed1778@ gmail.com

Received: 21/01/2018

Accepted: 18/02/2018

\begin{abstract}
The current study aimed to evaluate the effects of exposing pre-mature Dandarawi roosters to different light-emitting diode (LED) light colors on testicular development, serum testosterone levels, and sperm motility and velocity. Seventy-five roosters, 16 weeks old, were assigned to 5 experimental groups each with three replicates of five birds per pen. Roosters of each experimental group were subjected to a different light color using Nine-watt red, yellow, green, blue and white LED bulbs from 16 to 36 weeks of age. Twenty-five semen pools were obtained over the last ten weeks ( 5 pools from each treatment) to evaluate sperm motility and velocity. Blood serum was collected to evaluate testosterone levels and the testicular growth was assessed. The results showed that green light hindered the testicular growth and had adverse effects on almost all studied semen traits $(\mathrm{P}<0.05)$. Both green and blue light significantly lowered circulating testosterone levels compared to other experimental groups $(\mathrm{P}<0.0001)$. Roosters subjected to red light exhibited significantly higher percentages of total and progressive motile spermatozoa, a greater number of spermatozoa per ml, higher values of curve linear velocity (VCL), average path velocity (VAP) and straight linear velocity (VSL) and finally lower percentages of slow sperm as compared with roosters exposed to green, blue and white light. Roosters exposed to yellow light showed comparable results of testicular growth, serum testosterone concentrations and percentages of total motile, progressive and rapid spermatozoa to those exposed to red light. These results indicate that red and yellow light has better effects on reproduction and sperm quality than white and blue light, and that green light imposes adverse effects on reproduction in Dandarawi roosters.
\end{abstract}

Key words: Light color - testicular development - testosterone concentrations - sperm quality 
M. A. M. Sayed and Mostafa Galal Abdelfatah

\section{INTRODUCTION}

Light is a critical factor influencing growth and egg laying performance in poultry species. A significant amount of research was carried out on manipulating the photoperiod and light intensity to stimulate birds' growth, sexual maturity and reproductive performance which have greatly contributed to the understanding of the birds' physiological responses to different lighting programs. Incandescent lamps have been used for decades to illuminate poultry houses as it produces wide spectra of light. However, with the increased desire to reduce electricity costs in poultry sheds and the emerging of new technologies, fluorescent bulbs and lightemitting-diodes were taken into consideration to replace the uneconomic utilization of incandescent lamps. The duration and intensity of light are not the only factors that regulate the bird's physiological responses. Also, exposure to different light wavelengths was found to have a significant effect. For instance, exposure to green and blue light was found to stimulate testosterone secretion and enhance growth in broiler chickens (Rozenboim et al., 1999; Cao et al., 2008). On the other hand, earlier studies have shown that short wavelengths (green or blue) possess inhibitory effects on gonadal development (Benoit and Ott, 1944; Ishibashi and Kato, 1951; Oishi and Lauber, 1973). More recently, the green light was suggested to inhibit reproduction in birds (Baxter et al., 2014); and this inhibitory effect could be attributed to the secretion of serotonin from the retina and the hypothalamus (Mobarkey et al., 2013). Yadav and Chaturvedi (2015) reported decreases in testicular volume, plasma testosterone levels and seminiferous tubules in Japanese quail exposed to white and blue
LED when compared to those subjected to red and green light. Furthermore, red and white light increased egg production than green light in laying hens (Baxter et al., 2014) and than blue light in breeder geese (Chang et al., 2016). From these reports, it can be concluded that the physiological responses to different light wavelengths are dissimilar among species. In addition to growth and egglaying performance, fertility is considered a pivotal trait for the poultry industry as it determines the rate of chick output. Semen quality is an important factor affecting the success of the fertilization process. The effects of light wavelengths on semen quality and sperm analysis are largely overlooked in the literature. Therefore, the main objectives of the current experiment were to study the effects of different light colors emitting from LED bulbs on testicular development, circulating testosterone concentrations and the quality of the produced sperm in Dandarawi roosters.

MATERIALS AND METHODS

Experimental birds and light
treatments

The current study was carried out at the Poultry Research Farm, Department of Poultry Production, Faculty of Agriculture, Assiut University. Seventyfive male Dandarawi chicks were raised under conventional lighting program of 22 hours light $(\mathrm{L})+2$ hours dark (D) for the first two weeks then the photoperiod was decreased to 8 hours $\mathrm{L}$ up to 16 weeks of age. Afterwards, roosters were randomly distributed into 5 experimental groups (each with three replicates of five roosters per pen) and housed in five identical rooms, each with three partitioned deep litter pens. Roosters in different chambers were subjected to different light wavelengths using Nine- 
watt red, yellow, green, blue and white LED bulbs. The height of the light sources was adjusted to give light intensities of 10 lux at the level of the birds. At 20 weeks of age, birds were photo-stimulated by a sudden transfer to 14 hours light; then photoperiod was gradually increased (15 minutes per week) to reach 16 hours L by 28 weeks of age. The roosters were provided with a commercial diet that gave $170 \mathrm{~g}$ crude protein, $28 \mathrm{~g}$ crude fat, $31.3 \mathrm{~g}$ crude fiber and 2750 kilo calorie, $30 \mathrm{~g}$ calcium and $6.8 \mathrm{~g}$ available phosphorus per each one $\mathrm{kg}$ diet throughout the experimental period (20 weeks).

\section{Semen collection and preparation}

Semen was collected five times from all roosters of all experimental groups (once every two weeks) starting from week 28 (after reaching the age of sexual maturity) to the end of the experimental period (36 weeks of age). The abdominal massage technique was used to collect the semen according to Burrows and Quinn (1937). All collected ejaculates from roosters within each experimental group were pooled, immediately diluted 1:1 using Lake and Ravie extender and placed in ice box until being transported to the Lab. Sperm concentration was assessed using Neubauer hemocytometer.

\section{Sperm motility and velocity}

Five semen pools for each experimental group were analyzed ( 25 pools in total) to assess sperm motility and velocity using CASA plugin for image-J (http://imagej.nih.gov/ij/) provided by National Institution of Health as described by Elsayed et al. (2015). A drop of warm $\left(37^{\circ} \mathrm{C}\right)$ diluted semen $(1$ : $40 \mathrm{v} / \mathrm{v}$ Lake and Ravie) was placed on a pre-warmed $\left(37^{\circ} \mathrm{C}\right)$ glass slide and covered by a glass cover. The slide was placed on Optika XDS-3 inverted microscope with phase contrast for examination using a magnification of $(400 \mathrm{x})$. The percentage of motile sperm, curvilinear velocity $(\mu \mathrm{m} / \mathrm{sec}$ VCL $)$, average path velocity ( $\mu \mathrm{m} / \mathrm{sec}$ VAP), straight linear velocity $(\mu \mathrm{m} / \mathrm{sec}$ VSL) and straightness $(\mathrm{STR}=\mathrm{VSL} / \mathrm{VAP})$ were evaluated. Sperm motion was recorded using Tucsen ISH 1000 camera at 30 frames/second mounted on the microscope. A minimum of three fields and 500 sperm tracks were examined using the CASA software. Spermatozoa with VAP $<10 \mu \mathrm{m} / \mathrm{s}$ and VSL $<5 \mu \mathrm{m} / \mathrm{s}$ are counted as static. Spermatozoa were categorized according to their velocity to slow $(10<\mathrm{VAP}<20 \mu \mathrm{m} / \mathrm{s})$, medium $(20$ $<\mathrm{VAP}<50 \mu \mathrm{m} / \mathrm{s}$ ) and rapid (VAP > 50 $\mu \mathrm{m} / \mathrm{s})$. The proportion of spermatozoa showing progressive motility was calculated as the number of spermatozoa exceeding $20 \mu \mathrm{m} / \mathrm{s}$ VAP and $80 \%$ STR divided by the number of motile spermatozoa.

\section{Testicular development and} testosterone concentrations

At the end of the experimental period, two $\mathrm{mL}$ of brachial blood was drawn from three birds per replicate, and whole blood was used to collect the serum. Serum samples were stored at $-20^{\circ} \mathrm{C}$ until assayed for testosterone concentrations. The hormone concentrations were determined using a testosterone enzyme immunoassay test kit (Biocheck, Inc. 323 Vintage Park Drive, Foster City, CA 94404). The absorbance was measured within 15 minutes using a microplate reader (Biotek ELX 808 IU) set at a wavelength of $450 \mathrm{~nm}$.

Following blood collection, the birds were humanely slaughtered, and the testes were weighed using a sensitive balance. The testis length and width were measured using a sensitive caliper. 


\section{Statistical analysis}

The data obtained were analyzed in a complete random design. The data were analyzed by ANOVA using the GLM procedure of SAS (SAS institute, 2009). When treatment effects were significant, differences between least squares means were tested using Duncan's multiplerange test (Duncan, 1955) and the differences were considered significant at the level of $\mathrm{P}<0.05$. Before analysis, all percentages were subjected to arcsine transformation to approximate normal distribution.

The following model was used for analysis of variance:

$$
Y i j=\mu+S i+E i j
$$

Where: Yij $=$ observation, $\mu=$ overall mean, $\mathrm{Si}=$ treatment effect, $\mathrm{Eij}=$ experimental errors.

\section{RESULTS}

The effects of light color on testicular development and serum testosterone levels are presented in Table 1.

Roosters exposed to red and yellow light had heavier absolute and relative weights of left testes $(\mathrm{P} \leq 0.05)$, longer width of left and right testes $(p \leq 0.05)$ when compared with those subjected to green light; while roosters exposed to white and blue light had intermediate values. The relative weights of the right testes did not differ among roosters exposed to red, yellow, white light and they were all significantly higher than those of roosters exposed to blue and green light $(\mathrm{P} \leq 0.004)$. The obtained results revealed lower circulating testosterone levels of roosters subjected to green and blue light when compared with other experimental groups $(\mathrm{P} \leq 0.0001)$.

Results of Table 2 shows the effects of light color on sperm number per $\mathrm{ml}$, motility, and velocity.
Roosters exposed to green light exhibited the least sperm concentration per $\mathrm{ml}$ $(\mathrm{P} \leq 0.0001)$, the highest percentages of immotile $(\mathrm{P} \leq 0.0001)$ and slow sperm $(\mathrm{P} \leq 0.0005)$, the lowest percentages of spermatozoa showing progressive motility $(\mathrm{P} \leq 0.0001)$, and smallest values of VAP, VSL $(\mathrm{P} \leq 0.0001)$, and straightness $\quad(\mathrm{STR}=\mathrm{VSL} / \mathrm{VAP}$; $\mathrm{P} \leq 0.0001)$. Compared with the other experimental groups, roosters exposed to red light recorded superior values of VCL, VAP, VSL $(\mathrm{P} \leq 0.0001)$ and sperm concentration per $\mathrm{ml}(\mathrm{P} \leq 0.0001)$, and had higher percentages of medium swimming sperm $\quad(\mathrm{P} \leq 0.0001)$ and the lowest percentages of slow sperms $(\mathrm{P} \leq 0.0005)$. Ejaculates from roosters which subjected to yellow light exhibited comparable proportions of total motile sperm, rapid swimming sperm, and spermatozoa showing progressive motility to those in the red light group. In addition, males exposed to yellow light returned ejaculates having higher values of VCL, VAP, VSL, and STR than those subjected to white, blue and green light $(\mathrm{P} \leq 0.0001)$. The proportions of total motile, rapid and progressively motile sperm, the number of sperm per ml, and the values of VAP, VSL, and STR did not differ significantly between roosters treated with white and blue light.

\section{DISCUSSION}

Our results regarding the effects of light color on testes growth strengthen previous observations in which short wavelengths have an inhibitory impact on testicular mass. In Leghorn cockerels exposed to different light wavelengths, birds reared under red, or white light had heavier testes weights than those grown under ultraviolet, blue and green light (Osol et al., 1984). 
In birds, the perception of light occurs through photoreceptors that are located in the retina, the pineal gland, and the hypothalamus. Retinal photoreceptors are responsible for sight and bird's responses related to growth and behavior; however, the retina is not involved in regulating reproduction (Wilson and Lindstorm, 2011). To prove that retina is not necessary for light stimulation of reproduction, Baxter et al. (2014) exposed sighted and blind chickens to red, green, blue, or white light. The results indicated that photostimulation did not differ between sighted and blind birds maintained under red or white light, and that red light was necessary to stimulate the reproductive axis. It is well established that controlling the circadian rhythm is the function of the pineal gland through the secretion of melatonin and that the organ is not critical for the perception of daylength (Nir et al., 1987; Baxter et al., 2014). However, the light that stimulates the reproductive axis is perceived by the hypothalamic photoreceptors (Saldanah et al., 1994; Baxter et al., 2014). This means that light must penetrate the skull and brain tissues to reach the hypothalamus and initiates its effects on the development of the reproductive system. When the hypothalamic photoreceptors perceive the light, gonadotropin-releasing hormone $(\mathrm{GnRH})$ is released into the hypophyseal portal system stimulating the anterior pituitary to release gonadotropins which in turn stimulate gonads' growth (Dunn et al., 2009). Spectra of longer wavelengths possess higher energy and are more capable of penetrating the skull and brain tissues than those of shorter wavelengths (Baxter et al., 2014). Therefore, shorter wavelengths require higher intensities in order to stimulate the hypothalamic photoreceptors (Pang et al., 1974; Prescott et al., 2003). This fact may explain our results in which red and yellow spectra resulted in heavier testes weights than did green and blue light. Because white light is made up of a mixture of different colors including red and yellow, no significant differences in testes weight and size were observed among roosters subjected to the three color treatments.

It is well known that there are two major types of cells necessary for the normal function of the testes. Leydig cells located in the interstitial compartment adjacent to the seminiferous tubules have the steroidogenic enzymes required for the production of testosterone and androstenedione (Johnson, 1986). Testosterone production relies on Leydig cells being stimulated by $\mathrm{LH}$, which is secreted into the peripheral circulation by the anterior pituitary in response to gonadotropin-releasing hormone $(\mathrm{GnRH})$ from the hypothalamus (McLachlan et al., 1996). The second type, Sertoli cells, is located within the seminiferous tubules and secretes inhibin, androgen binding protein, and estrogen and plays a pivotal role in spermatogenesis. The division of secondary spermatocytes into haploid spermatids is crucially dependent upon androgens including testosterone (Weinbauer et al., 2010). Therefore, we propose that the higher serum testosterone concentrations and consequently the higher sperm concentration per $\mathrm{ml}$ observed in the red and yellow light treated birds can be attributed to a higher secretion of $\mathrm{LH}$ from the anterior lobe of the pituitary gland. This assumption is supported by the findings of $\mathrm{Li}$ et al. (2014) who observed higher LH and FSH levels in chickens raised under long wavelengths 


\section{A. M. Sayed and Mostafa Galal Abdelfatah}

(red light) than those reared under short wavelengths.

Furthermore, because a large proportion of testicular mass is involved in spermatogenesis, testes size is sometimes used to estimate sperm production (Moller, 1988). Hence, the larger testis is predicted to produce more sperm than small testis. This interrelationship was reported in the house sparrow (Birkhead et al., 1994), and in zebra finch (Birkhead et al., 1993). Also, positive correlations between testes weights and sperm concentration were reported in chickens (Lee et al., 1999). These correlations also justify our findings where ejaculates from roosters raised under green light exhibited the lowest number of sperm per ml; while those of males reared under red light showed the highest sperm count per ml.

The effects of light color on sperm kinetics have never been published before in the literature. The results obtained from the current study indicate that light color not only exerts its effects on testicular growth and sperm concentration, but also significantly influences sperm quality. Roosters exposed to red light returned ejaculates with highest values of all sperm kinetics (VCL, VAP, and VSL) followed by those from males exposed to yellow, blue, white and green light, respectively. Straightness values were highest in red and yellow and lowest in green light treatment. Moreover, roosters exposed to red and yellow light recorded higher percentages of total motile, rapid and progressive sperm and had smaller proportions of slow sperm compared to other treatments. Ejaculates from the green light group showed the lowest sperm quality. Sperm velocity and progressive motility are of outmost importance and should be assessed together when evaluating sperm quality because they determine the success of sperms to traverse the oviduct and their ability to reach the site of fertilization (Sayed et al., 2017). Progressively motile sperms swimming with slow speed are unlikely competitive because they most likely fail to ascend the oviduct and do not approach the funnel. Likewise, not all rapid sperms are capable of reaching the ova because sperms swimming in small circles (not progressive) are simply not moving forward and also fail to reach the fertilization site (Sloter et al., 2006).

Hence, ejaculates having higher proportions of spermatozoa showing progressive motility with higher values of VSL are indicative of higher sperm mobility and better competence which is eventually reflected on the resultant fertility rates (Sayed et al., 2017). Our results indicate that roosters exposed to red light returned ejaculates with better sperm quality and are predicted to achieve better fertility rates compared to the rest of treatment groups.

\section{CONCLUSION}

In summary, exposing premature Dandarawi roosters to blue and green light resulted in smaller testes size and lower serum testosterone concentrations compared to those subjected to red, yellow and white light. Sperm analysis revealed that roosters exposed to red light had higher sperm concentration per $\mathrm{ml}$ and superior sperm quality based on all sperm kinetics, progressive motility and the sperm swimming speed than other treatment groups. 
Table (1): Effects of exposing Dandarawi roosters to different light color on testes development and serum testosterone concentrations $(\mathrm{ng} / \mathrm{ml})$.

\begin{tabular}{|c|c|c|c|c|c|c|c|}
\hline Traits & Red & Yellow & Green & Blue & White & $\begin{array}{c}\text { Pooled } \\
\text { SEM }\end{array}$ & P-value \\
\hline Body weight (g) & 2170 & 2194 & 2158 & 2312 & 2223 & 128.2 & 0.918 \\
\hline $\begin{array}{l}\text { Left testis weight } \\
\text { (g) }\end{array}$ & $26.06^{\mathrm{a}}$ & $21.49^{\mathrm{a}}$ & $8.37^{\mathrm{b}}$ & $19.02^{\mathrm{ab}}$ & $19.20^{\mathrm{ab}}$ & 3.85 & 0.050 \\
\hline Left testis (\%) & $1.20^{\mathrm{a}}$ & $1.00^{\mathrm{a}}$ & $0.39^{\mathrm{b}}$ & $0.81^{\mathrm{ab}}$ & $0.85^{\mathrm{ab}}$ & 0.17 & 0.046 \\
\hline $\begin{array}{l}\text { Right testis weight } \\
\text { (g) }\end{array}$ & $29.94^{\mathrm{a}}$ & $23.16^{\mathrm{a}}$ & $9.91^{\mathrm{b}}$ & $21.44^{\mathrm{a}}$ & $25.51^{\mathrm{a}}$ & 3.35 & 0.006 \\
\hline Right testis (\%) & $1.38^{\mathrm{a}}$ & $1.08^{\mathrm{a}}$ & $0.47^{\mathrm{b}}$ & $0.92^{\mathrm{b}}$ & $1.17^{\mathrm{a}}$ & 0.15 & 0.004 \\
\hline $\begin{array}{l}\text { Left testis width } \\
(\mathrm{cm})\end{array}$ & $2.62^{\mathrm{a}}$ & $2.80^{\mathrm{a}}$ & $1.86^{\mathrm{b}}$ & $2.38^{\mathrm{ab}}$ & $2.40^{\mathrm{ab}}$ & 0.21 & 0.048 \\
\hline $\begin{array}{l}\text { Right testis width } \\
(\mathrm{cm})\end{array}$ & $2.90^{\mathrm{a}}$ & $2.86^{\mathrm{a}}$ & $1.96^{\mathrm{b}}$ & $2.52^{\mathrm{ab}}$ & $2.52^{\mathrm{ab}}$ & 0.21 & 0.041 \\
\hline $\begin{array}{l}\text { Left testis length } \\
(\mathrm{cm})\end{array}$ & 5.08 & 4.96 & 3.62 & 4.64 & 4.28 & 0.39 & 0.104 \\
\hline $\begin{array}{l}\text { Right testis length } \\
(\mathrm{cm})\end{array}$ & 5.49 & 5.14 & 4.00 & 4.90 & 4.58 & 0.40 & 0.143 \\
\hline $\begin{array}{l}\text { Testosterone } \\
\text { concentration }\end{array}$ & $2.610^{\mathrm{a}}$ & $2.540^{\mathrm{a}}$ & $1.594^{\mathrm{b}}$ & $1.848^{\mathrm{b}}$ & $2.560^{\mathrm{a}}$ & 0.09 & 0.0001 \\
\hline
\end{tabular}

$\mathrm{a}$ and $b$ for main effects, means within main effects in the same row without common superscripts are significantly different.

$\mathrm{SEM}=$ standard error mean 
Table (2): Effects of exposing Dandarawi roosters to different light color on sperm concentration per ml, motility, swimming speed and sperm velocity.

\begin{tabular}{|l|c|c|c|c|c|c|c|}
\hline & Red & Yellow & Green & Blue & White & $\begin{array}{c}\text { Pooled } \\
\text { SEM }\end{array}$ & P-value \\
\hline Sperm Concentration & $743.00^{\mathrm{a}}$ & $560.33^{\mathrm{b}}$ & $219.66^{\mathrm{c}}$ & $548.00^{\mathrm{b}}$ & $473.33^{\mathrm{b}}$ & 46.48 & 0.0001 \\
$\times 10^{7} / \mathrm{ml}$ & & & & & & & \\
\hline Motility & $1.13^{\mathrm{c}}$ & $1.12^{\mathrm{c}}$ & $5.60^{\mathrm{a}}$ & $4.66^{\mathrm{ab}}$ & $3.91^{\mathrm{b}}$ & 0.50 & 0.0001 \\
\hline Immotile \% & $98.87^{\mathrm{a}}$ & $98.88^{\mathrm{a}}$ & $94.57^{\mathrm{c}}$ & $95.34^{\mathrm{bc}}$ & $96.09^{\mathrm{b}}$ & 0.49 & 0.0001 \\
Motile \% & $34.03^{\mathrm{a}}$ & $32.62^{\mathrm{a}}$ & $18.58^{\mathrm{c}}$ & $25.97^{\mathrm{b}}$ & $26.11^{\mathrm{b}}$ & 1.52 & 0.0001 \\
Progressive sperm \% & $64.84^{\mathrm{d}}$ & $66.26^{\mathrm{cd}}$ & $75.81^{\mathrm{a}}$ & $69.37^{\mathrm{bc}}$ & $69.98^{\mathrm{b}}$ & 1.09 & 0.0003 \\
Non-progressive \% & & & & & & & \\
\hline Swimming speed & & & & & & \\
\hline Slow \% & $11.52^{\mathrm{c}}$ & $17.86^{\mathrm{b}}$ & $27.68^{\mathrm{a}}$ & $17.98^{\mathrm{b}}$ & $24.02^{\mathrm{a}}$ & 1.62 & 0.0005 \\
Medium \% & $76.31^{\mathrm{a}}$ & $66.90^{\mathrm{c}}$ & $59.07^{\mathrm{e}}$ & $71.70^{\mathrm{b}}$ & $63.29^{\mathrm{d}}$ & 1.64 & 0.0001 \\
Rapid \% & $12.62^{\mathrm{a}}$ & $14.12^{\mathrm{a}}$ & $6.51^{\mathrm{b}}$ & $5.66^{\mathrm{b}}$ & $8.78^{\mathrm{ab}}$ & 1.09 & 0.021 \\
\hline Sperm velocity \& & & & & & & & \\
straightness & & & & & & & \\
\hline VCL $(\mu \mathrm{m} / \mathrm{sec})$ & $63.71^{\mathrm{a}}$ & $57.51^{\mathrm{b}}$ & $57.09^{\mathrm{b}}$ & $57.30^{\mathrm{b}}$ & $53.57^{\mathrm{c}}$ & 0.22 & 0.0001 \\
VAP $(\mu \mathrm{m} / \mathrm{sec})$ & $34.65^{\mathrm{a}}$ & $31.87^{\mathrm{b}}$ & $27.48^{\mathrm{d}}$ & $29.45^{\mathrm{c}}$ & $29.33^{\mathrm{c}}$ & 0.16 & 0.0001 \\
VSL $(\mu \mathrm{m} / \mathrm{sec})$ & $25.17^{\mathrm{a}}$ & $23.44^{\mathrm{b}}$ & $18.53^{\mathrm{d}}$ & $21.33^{\mathrm{c}}$ & $21.15^{\mathrm{c}}$ & 0.13 & 0.0001 \\
STR & $71^{\mathrm{a}}$ & $71^{\mathrm{a}}$ & $65^{\mathrm{c}}$ & $69^{\mathrm{b}}$ & $69^{\mathrm{b}}$ & 0.20 & 0.0001 \\
\hline
\end{tabular}

${ }^{\text {a-b-c-d-e }}$ For main effects, means within a row without common superscripts differ significantly $\mathrm{P}$ $<0.05$.

Abbreviations: VCL, curvilinear velocity; VAP, average path velocity; VSL, straight line velocity; STR = VSL/VAP. 


\section{REFERENCES}

Baxter, M.; Joseph, N.; Osborne, V. R.; and Bedecarrats, G. Y., 2014. Red light is necessary to activate the reproductive axis in chickens independently of the retina of the eye. Poult. Sci. 93: 1289-1297.

Benoit, J.; and Ott, L., 1944. External and internal factors in sexual activity: Effects of irradiation with different wavelengths on the mechanisms of photostimulation of the hypophysis and on testicular growth in the immature duck. Yale. J. Biol. Med. 17: 27-46.

Birkhead, T. R.; Pellatt, E. J.; and Fletcher, F., 1993. Selection and utilization of spermatozoa in the reproductive-tract of the female Zebra Finch Taeniopygia-Guttata. Journal of Reproduction and Fertility 99: 593600.

Birkhead, T. R.; Veiga, J. P.; and Moller, A. P., 1994. Male sperm reserves and copulation behavior in the House Sparrow, Passer-Domesticus. Proceedings of the Royal Society BBiological Sciences 256: 247-251.

Burrows, W.H.; Quinn, J.P., 1937. The collection of spermatozoa from the domestic fowl and turkey. Poult. Sci. 16: 19-24.

Cao, J.; Liu, W.; Wang, Z.; Xie, D.; Jia, L.; and Chen, Y., 2008. Green and blue monochromatic lights promote growth and development of broilers via stimulating testosterone secretion and myofiber growth. Journal of Applied Poultry Research 17: 211-218.

Chang, S. C.; Lin, M. J.; Zhuang, Z. X.; Huang, S. Y.; Lin, T. Y.; Jea, Y. S.; Fan, Y. K.; and Lee, T. T., 2016. Effect of monochromic light-emitting diode light with different color on the growth and reproductive performances of breeder geese. Asian-Australasian Journal of Animal Sciences 29: 830837.

Duncan, D.B., 1955. Multiple range and multiple F. tests. Biometrics, 11: 1-42.

Dunn, I. C.; Ciccone, N. A.; and Joseph, N. T., 2009. Endocrinology and genetics of the hypothalamic-pituitarygonadal axis. In "Biology of Breeding Poultry" (P. M. Hocking, ed.), Vol. 29: pp. 61-88.

Elsayed, M.; El-Sherry, T. M.; and Abdelgawad, M., 2015. Development of computer-assisted sperm analysis plugin for analyzing sperm motion in microfluidic environments using Image-J. Theriogenology 84: 13671377.

Ishibashi, T.; and Kato, Y., 1951. Effects of irradiation with different wavelengths on development of the gonad in the fowl. Sci. Bull. Fac. Agr. Kyushu Univ. 13: 392-395.

Johnson, A. L., 1986. Reproduction in the Male. In: Avian Physiology. SpringerVerlag, New York, NY. Chp. 19

Lee, Y. P.; Lee, S. L.; Ho, Y. J.; and Chen, T. L., 1999. Behavioural responses of cockerels to semen collection and their influence on semen characteristics. British Poultry Science 40: 317-322.

Li, D. Y., Zhang, L., Yang, M. Y., Yin, H. D., Xu, H. L., Trask, J. S., Smith, D. G.; Zhang, Z. C.; and Zhu, Q., 2014. The effect of monochromatic light-emitting diode light on reproductive traits of laying hens. Journal of Applied Poultry Research 23: 367-375. 
McLachlan, R. I.; Wreford, N. G.; Odonnell, L.; deKretser, D. M.; and Robertson, D. M., 1996. The endocrine regulation of spermatogenesis: Independent roles for testosterone and FSH - Commentary. Journal of Endocrinology 148: 1-9.

Mobarkey, N.; Avital, N.; Heiblum, R.; and Rozenboim, I., 2013. The effect of parachlorophenylalanine and active immunization against vasoactive intestinal peptide on reproductive activities of broiler breeder hens photostimulated with green light. Biology of Reproduction 88: 1-7.

Moller, A. P., 1988. Testes size, ejaculate quality and sperm competition in birds. Biological Journal of the Linnean Society 33: 273-283.

Nir, I.; Allen, A. E.; and Pang, S. F., 1987. Pineal, retinal, serum melatonin, and $\mathrm{N}$-acetylserotonin rhythms in chicks on reversing light regimen and eye covering. Journal of Pineal Research 4: 305-314.

Oishi, T.; and Lauber, J. K., 1973. Photoreception in the photosexual response of quail. II. Effects of intensity and wavelength. Amer. J. Physiol. 225: 880-886.

Osol, G.; Foss, D. C.; and Carew, L. B., 1984. Effects of selected wavelengths of light on reproductive development in cockerels. General and Comparative Endocrinology 55: 227-232.

Pang, S. F.; Ralph, C. L.; and Reilly, D. P., 1974. Melatonin in chicken brain Its origin, diurnal-variation, and regional distribution. General and Comparative Endocrinology 22: 499506.

Prescott, N. B.; C. M. Wathes, and J. R. Jarvis., 2003. Light, vision and the welfare of poultry. Anim. Welfare 12: 269-288.

Rozenboim, I.; Biran, I.; Uni, Z.; Robinzon, B., and Halevy, O. 1999. The effect of monochromatic light on broiler growth and development. . J. of Poult. Sci. 78: 135-138.

Saldanah, C. J.; Leak, R. K.; and Silver, R., 1994. Detection and transduction of daylength in birds. Psychoneuroendocrinology 19: 641656.

SAS institute., 2009. User's Guide Version, 9.2, 2002-2009., SAS institute Inc., Cary, NC, USA.

Sayed, M. A. M.; F. M. K. Abouelezz, and Amira, A. M. A., 2017. Analysis of sperm motility, velocity and morphometry of three Egyptian indigenous chicken strains. Egypt. Poult. Sci. 37:1173-1185.

Sloter, E.; Schmid, T. E.; Marchetti, F.; Eskenazi, B.; Nath, J.; and Wyrobek, A. J., 2006. Quantitative effects of male age on sperm motion. Human Reproduction 21: 2868-2875.

Wilson, M.; and Lindstrom, S. H., 2011. What the bird's brain tells the bird's eye: the function of descending input to the avian retina. Visual Neuroscience 28: 337-350.

Weinbauer, G. F.; C. M. Luetjens; M. Simoni and E. Nieschlag., 2010. Physiology of Testicular Function.Andrology: Male Reproductive Health and Dysfunction, Third Edition

Yadav, S.; and Chaturvedi, C. M., 2015. Light color and intensity alters reproductive/seasonal responses in Japanese quail. Physiology \& Behavior 147: 163-168. 


$$
\text { الملخص العربحى }
$$

\section{تأثير لون الاضاءة المنبعة من لمبات الليد علي نمو الخصيتين، تركيز هرمون التستوستثيرون

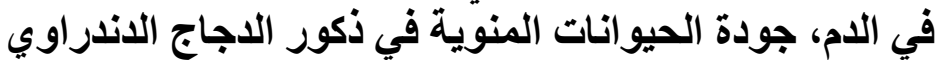

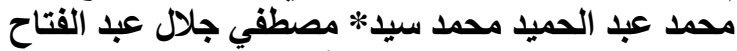

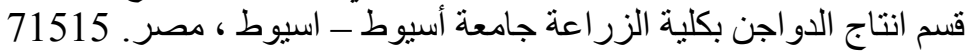

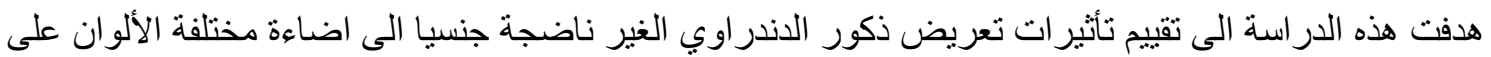

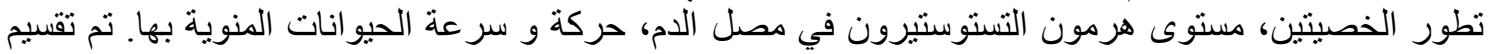

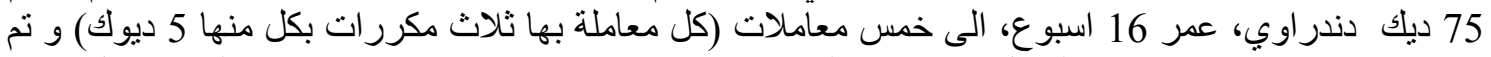

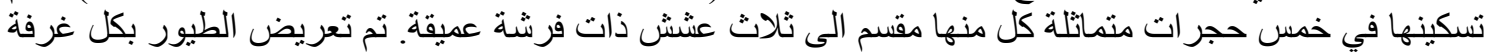

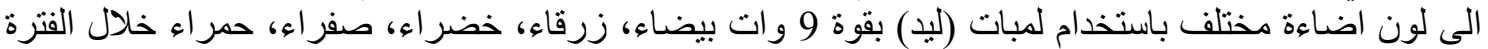

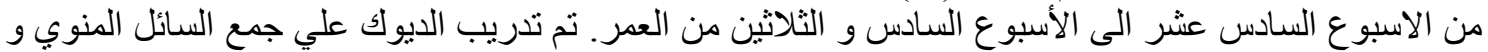

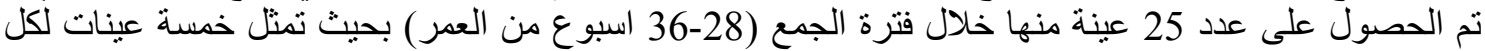

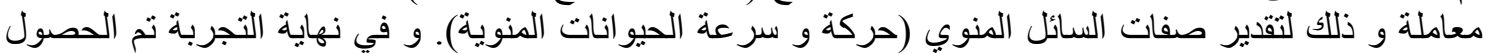

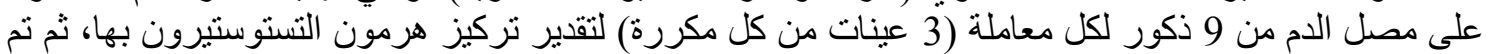

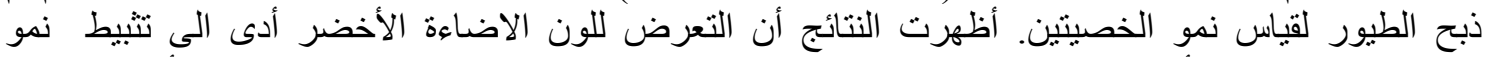

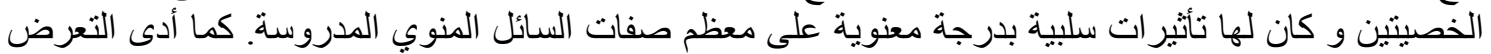

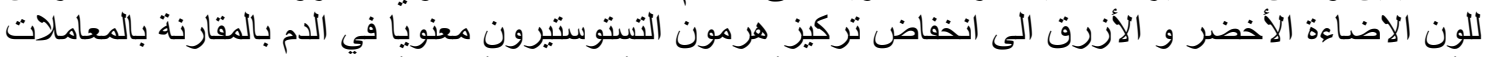

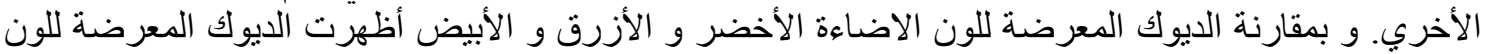

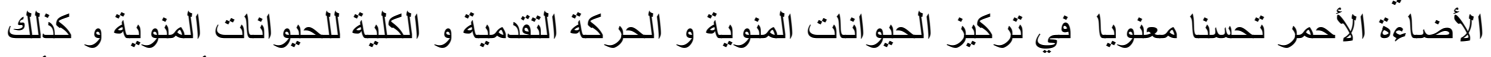

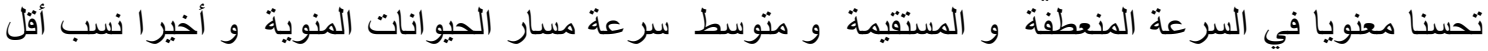

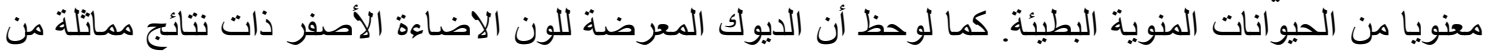

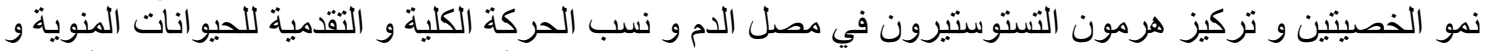

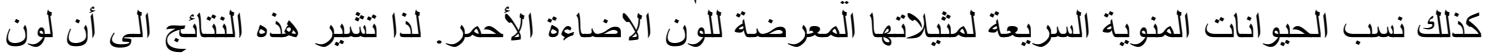

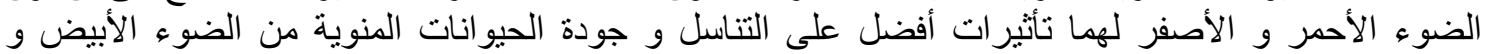

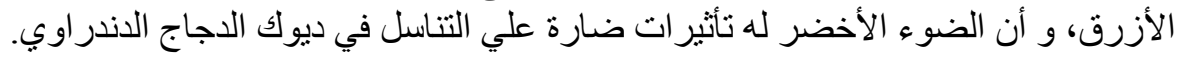

